\title{
Economia política da pirataria na Somália: bases para uma abordagem transformativa*
}

Gilberto Carvalho de Oliveira'

\section{Resumo}

Este artigo analisa a atual onda de pirataria nas costas da Somália à luz do modelo de economias de guerra proposto por Michael Pugh e Neil Cooper. Segundo esses autores, três tipos de economias florescem nos conflitos prolongados economia de combate, economia subterrânea e economia de sobrevivência - cujos objetivos são, respectivamente, financiar as atividades de combate, gerar lucros pessoais e prover recursos mínimos de subsistência às populações marginalizadas. Com base em indícios e evidências empíricas que permitem considerar que a pirataria na Somália desempenha essas três funções, argumenta-se que a atual intervenção contra a pirataria patrocinada pelas Nações Unidas, ao concentrar-se na violência direta que se observa no mar, não é sustentável na medida que não ambiciona transformar os fatores e as dinâmicas que tornam a pirataria numa alternativa economicamente atrativa aos olhos das populações locais. Diante desta constatação, sugere-se que o tema da pirataria na Somália seja redirecionado para uma agenda crítica, onde o problema deixe de ser tratado como mero foco de desordem no mar e passe a ser abordado em sua dimensão político-econômica, dentro de uma perspectiva transformativa que leve em consideração não só os aspectos locais, mas também as suas ligações regionais.

Palavras-chave: Economias de guerra. Pirataria na Somália. Transformação de conflitos.

\footnotetext{
* Recebido em 07.10.10. Aprovado em 08.12.2010.

${ }^{1}$ Doutorando em Política Internacional e Resolução de Conflitos na Faculdade de Economia/Centro de Estudos Sociais, Universidade de Coimbra (Portugal). Seus interesses de investigação concentram-se no âmbito disciplinar dos Estudos para a Paz, Estudos dos Conflitos e Estudos Críticos de Segurança, com ênfase nos seguintes tópicos: peacekeeping, peacebuilding, transformação de conflitos e teoria da securitização. Contactos: gilbertooliv@gmail.com ou gilbertooliv@ces.uc.pt
} 


\section{Introdução}

Em 2008, o Conselho de Segurança das Nações Unidas emitiu um conjunto de resoluções, chamando a atenção internacional para o aumento na incidência de ataques de piratas nas costas da Somália e autorizando o uso da força no combate à pirataria, não só em alto mar, mas também no interior do mar territorial daquele país. Em resposta a essas resoluções, diversas operações navais de combate à pirataria foram iniciadas no final de 2008 e intensificadas ao longo de 2009 e 2010 sem, contudo, produzirem resultados que apontem para a erradicação das ações dos piratas naquela região. Argumenta-se, neste artigo, que as resoluções do Conselho de Segurança e as operações navais por elas desencadeadas não constituem uma resposta sustentável ao problema da pirataria na Somália, devido à seguinte razão: a resposta internacional baseia-se numa abordagem coerciva, focada na violência direta que se manifesta no mar, e não levam em consideração os fatores e as dinâmicas que tornam a pirataria uma alternativa econômica atrativa para as populações locais. Em consequência, ainda que o patrulhamento naval consiga frustrar parte das ações dos piratas, os incentivos e as redes que sustentam a pirataria continuam presentes na Somália, mantendo no horizonte a possibilidade de recorrência ou eclosão de novas ondas de ataques na região.

Considerando esse argumento, este artigo problematiza a pirataria na Somália dentro de uma abordagem crítica, o que requer, à partida, a superação de duas visões ortodoxas sobre o tema: a tradicional perspectiva da pirataria como mera questão de ordem no mar e a concepção do pirata como um ser bárbaro, irracional, naturalmente motivado por instintos de violência. ${ }^{2}$ Entende-se que essas

2 Essa concepção ortodoxa da pirataria tem suas origens no pensamento de Cícero (106-43 $\mathrm{AC}$ ). O pensador romano definiu o pirata como o "inimigo não justo" e contra quem a "comunidade politicamente organizada" não se obrigava a observar quaisquer "regras de humanidade, lei e compromisso" (THORUP, 2009, p. 403). Essa visão, que atravessou a Idade Média e chegou aos séculos XVI e XVII como visão dominante, foi apropriada por Gentili (1552-1608), Bacon (1561-1616) e Grotius (1583-1645), cujas obras continuam a ser referências no pensamento sobre a pirataria. Deve-se destacar, ainda, que esses autores foram contemporâneos da expansão marítima européia e, como tal, testemunharam o nascimento de uma "real ordem nos oceanos, dentro da qual a pirataria passava a constituir um problema nas relações entre as nações” (ANDERSEN, 2009, p. 88). Essa concepção clássica do pirata (definido como inimigo de toda a humanidade e perturbador da ordem internacional estabelecida) ainda persiste no Direito Internacional contemporâneo: na 
duas visões, embora feitas à medida para justificar o uso da força contra a pirataria, pouco ou nada contribuem para uma abordagem comprometida com a transformação dos fatores e das dinâmicas subjacentes ao problema. Desse modo, buscando evitar a abordagem ortodoxa do tema, pretende-se examinar a pirataria na Somália à luz do modelo de economia política dos conflitos armados proposto por Pugh e Cooper (2004). Através desse prisma, a pirataria é esvaziada de sua carga normativa e é reconceptualizada como economia de guerra com base em seus aspectos funcionais. Essa reconceptualização - considerada não só no contexto local do conflito na Somália, mas também no âmbito das suas conexões regionais - amplia consideravelmente o espaço de reflexão crítica e traz importantes implicações do ponto de vista da proposição de políticas para a transformação das dinâmicas que alimentam a pirataria na região do Chifre da África.

Dentro desta proposta analítica, este artigo segue estruturado em três seções. Na primeira, o modelo de economia política dos conflitos de Pugh e Cooper (2004) é contextualizado dentro da atual bibliografia sobre economias de guerra. Partindo do debate usualmente designado pela expressão 'greed and grievance'3 (BERDAL; MALONE, 2000; BALLENTINE; SHERMAN, 2003), busca-se destacar, primeiramente, de que forma a dimensão econômica dos conflitos armados é reinterpretada no contexto das 'novas guerras' do pós-Guerra Fria; em seguida, busca-se ressaltar de que maneira o trabalho de Pugh e Cooper procura superar algumas limitações existentes no debate 'greed vesus grievance'. Nesse sentido, três aspectos são destacados: a tipologia funcional das economias de guerra proposta pelos autores (economia de combate, economia subterrânea e economia de sobrevivência), o papel da regionalização na economia política dos conflitos armados e a importância da compreensão das economias de guerra e da regionalização no âmbito da transformação de conflitos.

A seção seguinte inclui um estudo de caso sobre a pirataria na Somália, onde diversos indícios e evidências empíricas são examinados à luz do modelo de

caracterização da pirataria contida na Convenção das Nações Unidas sobre o Direito no Mar, encontra-se subjacente a noção do pirata como inimigo de todos os Estados e que, por esta razão, todos os Estados têm o dever de combater (CNUDM, 1982, art. 100).

3 'cobiça versus ressentimento' (tradução nossa). 
economia política dos conflitos proposto por Pugh e Copper (2004). Adotam-se, nesse sentido, dois passos analíticos. Primeiramente, a pirataria somali é enquadrada nos três descritores funcionais propostos pelos dois autores: economia de combate (situação em que a pirataria funciona como fonte de financiamento das atividades de combate); economia subterrânea (situação em que a pirataria é motivada exclusivamente por lucros pessoais); e economia de sobrevivência (situação em que a pirataria funciona como fonte de recursos para a subsistência de populações empobrecidas e marginalizadas). Feito esse esforço de tipificação, busca-se, em seguida, examinar de que forma essas três economias da pirataria se articulam nos níveis local e regional.

Na última seção, são destacadas as limitações da intervenção naval contra a pirataria em curso desde 2008, tendo em vista os complexos incentivos e conexões regionais da pirataria identificados no estudo de caso da seção anterior. Em função dessas limitações, defende-se o deslocamento do tema da pirataria na Somália para uma agenda crítica, onde o problema deixe de ser abordado como mero foco de desordem no mar e passe a ser abordado como economia política. Dentro dessa abordagem alternativa, torna-se possível adotar uma perspectiva transformativa que leve em consideração não só o fato de a pirataria envolver atividades predatórias e violentas, mas também o fato dela prover uma série de benefícios funcionais. A compreensão do problema dentro dessa dualidade tem implicações cruciais para a transformação do conflito na Somália, na medida em que permite mapear os benefícios e os custos da pirataria e, com base nesse conhecimento, propor desincentivos à violência e incentivos que direcionem os atores envolvidos com a pirataria para alternativas econômicas mais pacíficas.

\section{A dimensão econômica dos conflitos armados contemporâneos}

A desintegração do mundo bipolar produziu um impacto significativo na análise dos conflitos armados. Autores como Kaldor (1999), Keen (1998) e Reno (1999), ao observarem a decadência de alguns Estados devido ao fim dos subsídios distribuídos pelas duas superpotências da Guerra Fria, perceberam que uma nova conflitualidade emergia em regiões como a África e o leste europeu. Segundo esses 
autores, a redução da capacidade do Estado no monopólio do uso da força, associada à disponibilidade de grandes quantidades de armamento barato no mercado mundial, produziu uma mudança fundamental no caráter da guerra: o confronto entre Estados dotados de forças armadas disciplinadas em busca de uma vitória militar decisiva - tal como prevalecia nas 'velhas guerras' clausewitzianas - transformava-se, no contexto das chamadas 'novas guerras', numa mistura de grupos militares e civis que usavam a violência armada, não raras vezes, para extrair vantagens econômicas privadas, inclusive através de atividades criminosas (KALDOR, 1999, p. 102-110).

O atual debate sobre as economias de guerra nasce no contexto dessas 'novas guerras' e busca, em seu momento inicial, desafiar o conjunto das narrativas que tentam explicar a eclosão, a frequência e a persistência dos conflitos armados com base nos ressentimentos provocados pelas questões identitárias. ${ }^{4} \mathrm{O}$ marco desse momento inicial é o debate conhecido como 'cobiça versus ressentimento, ${ }^{5}$ lançado por Collier e Hoeffler (1998) e consolidado no amplamente citado Greed and Grievance: Economic Agendas in Civil Wars (BERDAL; MALONE, 2000). Nesse debate, as narrativas centradas nas questões identitárias, que geralmente identificam os ressentimentos (grievances) como a motivação principal dos conflitos, são contestadas por outro conjunto de narrativas que identifica a cobiça (greed) - entendida como busca de riqueza e captação de recursos com fins privados e de forma não oficial - como sendo a principal motivação para a deflagração e a perpetuação dos conflitos armados contemporâneos (COLLIER, 2000, p. 91-110; KEEN, 2000, p. 24-5; RENO, 2000, p. 64).

\footnotetext{
4 Uma das referências centrais das narrativas de 'ressentimento' é Edward Azar com sua teoria do conflito social prolongado (protracted social conflict). Segundo Azar, os ressentimentos resultantes das privações humanas (traduzidas em termos de necessidades de segurança, de desenvolvimento, de acesso político e de manifestação cultural e religiosa) são as causas mais profundas dos conflitos prolongados. Nas palavras do autor, "os ressentimentos resultantes das privações das necessidades são geralmente expressos coletivamente. A falha da autoridade na reparação desses ressentimentos cultiva um nicho para o desenvolvimento de um conflito social prolongado" (AZAR, 1990, p. 9).

5 Tradução nossa para a expressão 'greed versus grievance'.
} 
O passo seguinte desse debate, consolidado no livro editado por Ballentine e Sherman (2003), procura desafiar o caráter polarizado das narrativas 'greed and grievance'. Segundo esses dois autores, a dicotomia "conflito étnico versus conflito por recursos", ao apresentar explanações mutuamente excludentes, deixa de observar as interações entre as dinâmicas políticas e econômicas que ocorrem com frequência ao longo do conflito (BALLENTINE; SHERMAN, 2003, p.10). Dessa forma, não se pode adotar um prisma unidimensional - seja ele o da guerra étnica, seja ele o da guerra por recursos naturais (CATER, 2003, p. 20) - uma vez que os incentivos econômicos não podem ser considerados a causa única e primária dos conflitos armados (BALLENTINE, 2003, p. 260). Por essa razão, ainda que o foco na dimensão econômica seja crucial na análise dos conflitos contemporâneos, é preciso ir além das limitações desnecessárias da dicotomia 'greed and grievance' (BALLENTINE; SHERMAN, 2003, p. 6), a fim de adotar uma perspectiva mais abrangente que considere a política econômica dos conflitos. Desse ponto de vista, a importância dos incentivos econômicos pode ser ressaltada sem, contudo, negligenciar as oportunidades e ressentimentos relativos a outros fatores políticos, ideológicos e estratégicos (BALLENTINE, 2003, p. 259).

Esse foco na economia política dos conflitos armados é retomado por Pugh e Cooper (2004), dentro de uma abordagem que enfatiza o papel das economias de guerra, destaca as ligações regionais dessas economias e ressalta a importância desses aspectos no âmbito da transformação de conflitos. Segundo os autores, o modelo de construção da paz das Nações Unidas já leva em consideração, desde os anos 1990, a economia política dos conflitos; porém, "as agendas econômicas introduzidas nas receitas de intervenção internacional tendem a negligenciar aspectos cruciais das economias de guerra, especialmente as suas ligações regionais e os aspectos funcionais das economias subterrâneas" (PUGH; COOPER, 2004, p. 3). Essa negligência, segundo os autores, produz sérias dificuldades à transformação do conflito (PUGH; COOPER, 2004, p. 236-7), na medida que deixa de considerar os benefícios funcionais produzidos por essas economias. Dentro desse contexto geral, três aspectos do trabalho de Pugh e Cooper são cruciais para os propósitos deste artigo e, por essa razão, são desenvolvidos nos subtópicos a seguir: a tipificação das economias de guerra segundo seus aspectos funcionais; as interações das economias de guerra dentro dos 'complexos regionais de conflitos'; e as implicações dos dois aspectos anteriores na transformação de conflitos. 


\subsection{Tipologia das economias de guerra}

De acordo com Pugh e Cooper (2004, p. 8), a bibliografia sobre a dimensão econômica das 'novas guerras' emprega alguns termos chave, tais como 'criminosos', 'ilegais' e 'não oficiais', para designar comportamentos econômicos 'desviantes' em oposição a outros tipos de comportamentos 'corretos', que poderiam ser designados pelos termos 'autorizados', 'legais' e 'oficiais'. No entanto, nas situações onde prevalece um vácuo legal - tal como geralmente ocorre nas guerras - essa rígida distinção normativa entre dois tipos de comportamentos econômicos opostos mostra-se "conceptualmente falsa e apresenta limitado valor descritivo e analítico", na medida em que muitas das chamadas atividades 'ilegais' são toleradas ou até mesmo encorajadas por autoridades 'oficias' (PUGH; COOPER, 2004, p. 8). Segundo esses autores, a ausência de fronteiras entre o 'legal' e o 'ilegal' ocorre por diversas razões: porque oferece oportunidades de enriquecimento às elites; porque produz efeitos sociais positivos que possibilitam a sobrevivência de pessoas pobres e marginalizadas; ou porque geram recursos para o financiamento das ações de combate (PUGH; COOPER, 2004, p. 8). A essa linha de pensamento poder-se-ia acrescentar o argumento de Keen (2000, p. 19), segundo o qual a noção da guerra como colapso do sistema econômico e ascensão da barbárie é questionável. Segundo esse autor, em vez do conflito representar a queda de um sistema particular, ele representa, na verdade, a emergência de um sistema econômico alternativo e orientado para extrair benefícios da violência, o que torna "a guerra a continuação da economia por outros meios"6 (KEEN, 2000, p. 27).

Desse modo, considerando que os termos 'criminalidade' ou 'ilegalidade' refletem "construções sociais dominantes destinadas a deslegitimar atividades econômicas particulares," Pugh e Cooper defendem o emprego da expressão 'economias de guerra' para designar todos os tipos de comportamentos econômicos adotados no decorrer do conflito, independentemente de suas conotações normativas (2004, p. 8). Nesse sentido, os autores identificam três tipos de economias de guerra: economia de combate, economia subterrânea e economia de sobrevivência. ${ }^{7}$

${ }^{6}$ Numa paródia à máxima de Clausewitz de que "a guerra é a continuação da política por outros meios".

7 Nomenclatura do autor para os seguintes termos empregados por Pugh e Cooper (2004, p. 8): combat, shadow, and coping economies. 
A economia de combate (combat economy) relaciona-se à condução da guerra e engloba não só o controle da produção e da extração de recursos econômicos para sustentar as operações de combate, mas também as estratégias econômicas predatórias adotadas para a destruição dos recursos que possam fortalecer a capacidade de luta dos grupos oponentes. Os agentes econômicos centrais nessa economia são as facções em combate, sejam elas militares ou grupos armados não estatais (PUGH; COOPER, 2004, p. 8-9).

A economia subterrânea (shadow economy) refere-se à extração de lucro pessoal e engloba as atividades conduzidas fora dos mecanismos de regulação do Estado. Os agentes econômicos - que variam das elites empresariais em busca de lucro até as populações empobrecidas em luta pela sobrevivência - agem motivados por objetivos não militares, aproveitando os problemas econômicos e as oportunidades trazidas pela erosão da autoridade do Estado para obterem ganhos pessoais (PUGH; COOPER, 2004, p. 9).

A economia de sobrevivência (coping economy) engloba as atividades econômicas destinadas a prover mecanismos de enfrentamento das duras condições impostas pelo conflito, possibilitando, assim, a satisfação das necessidades básicas de subsistência das populações pobres e marginalizadas. Ainda que a economia de sobrevivência confunda-se, muitas vezes, com a economia subterrânea, a sua especificidade é a extração de recursos para subsistência dentro de mínimos padrões de vida e não para a acumulação de riqueza (PUGH; COOPER, 2004, p. 9).

Embora essa tipificação não corresponda, na prática, a limites tão definidos, podendo-se verificar sobreposições entre os três tipos de economias nas situações concretas, deve-se destacar que a terminologia proposta por Pugh e Cooper é conceptualmente útil enquanto ferramenta de análise e contribui para simplificar e organizar a abordagem da dimensão econômica dos conflitos armados. 


\subsection{Dimensão regional das economias de guerra}

Segundo Pugh e Cooper (2004, p. 23), uma deficiência a ser notada no debate sobre a economia política dos conflitos é a ausência de articulação da esfera local com a esfera regional. Considerando que as ligações regionais são suficientemente fortes a ponto de justificar uma visão integrada da segurança dos Estados situados próximos uns dos outros, ${ }^{8}$ Pugh e Cooper recorrem ao conceito de 'complexo regional de conflito', originalmente formulado por Wallensteen e Sollemberg (1998), a fim de salientarem determinadas situações onde conflitos muito próximos e interconectados formam redes transnacionais mutuamente reforçadas que contribuem para tornar os conflitos mais prolongados e persistentes (PUGH; COOPER, 2004, p. 25). Segundo os dois autores, essas interconexões regionais ocorrem, basicamente, através de quatro tipos de redes: econômicas, militares, políticas e sociais. As redes econômicas atuam, por exemplo, através da abertura de corredores para o escoamento de mercadorias, coleta privada de taxas no comércio de produtos agrícolas, sonegação fiscal e deslocamento de actividades ligadas à economia subterrânea de um lado para o outro das fronteiras (PUGH; COOPER, 2004, p. 26-30). As redes militares caracterizam-se, basicamente, pela exploração do mercado regional de armas e do mercado de mercenários (PUGH; COOPER, 2004, p. 30-2). As redes políticas produzem alianças entre lideranças políticas de Estados vizinhos, utilizando riquezas naturais, como minérios e pedras preciosas por exemplo, para o pagamento da ajuda entre os aliados (PUGH; COOPER, 2004, p. 32-3). As redes sociais atuam na criação de oportunidades de emprego dentro das estruturas alternativas de comércio, principalmente no âmbito das economias subterrâneas regionais e no âmbito do comércio de produtos de subsistência nas comunidades fronteiriças; atuam, também, no âmbito dos clãs ou famílias, provendo recursos essenciais à sobrevivência econômica das comunidades empobrecidas nas regiões de fronteira; além disso, englobam a ação das diásporas, cujo papel é importante não só na remessa de ajuda financeira aos familiares que permanecem nas regiões em conflito, mas também na sustentação de economias subterrâneas nas regiões de fronteira (PUGH; COOPER, 2004, p. 34-5).

8 Conforme defende a Escola de Copenhagen com seu conceito de 'complexo regional de segurança' (BUZAN et al., 1998). 


\subsection{Impactos na transformação}

O ponto fundamental a destacar em relação às redes regionais comentadas no subtópico anterior é o fato delas contribuirem para a criação das condições que favorecem o desenvolvimento das economias de guerra (PUGH; COOPER, 2004, p. 35). Essas economias não só burlam o controle estatal sobre a exploração e a distribuição dos recursos, como também criam um sistema socioeconômico alternativo de geração de empregos e movimentação de mercadorias que provê os mecanismos de sobrevivência das populações locais (PUGH; COOPER, 2004, p. 40). Portanto, se de um lado as economias subterrâneas abrem espaço para que elites econômicas auto-interessadas explorem a "mistura de corrupção, fraca capacidade governativa do Estado e porosidade das fronteiras" para a extração de benefícios financeiros pessoais, de outro lado elas exercem uma importante função social ao criarem condições para que as pessoas pobres e marginalizadas enfrentem a dura realidade do conflito e consigam satisfazer suas necessidades básicas de subsistência (PUGH; COOPER, 2004, p. 225). Em função desses benefícios, a continuidade da violência passa a ser vantajosa para grande parte dos atores inseridos no contexto do conflito, o que aumenta a resistência aos esforços voltados para a paz (PUGH; COOPER, 2004, p. 36).

Essa constatação, segundo Pugh e Cooper, tem uma importância crucial do ponto de vista da transformação de conflitos, embora, paradoxalmente, seja sistematicamente negligenciada pelas estratégias internacionais de construção da paz (PUGH; COOPER, 2004, p. 220). O modelo liberal que norteia as estratégias externas de intervenção, guiado pelo "paradigma do desenvolvimento através do livre mercado" (PUGH; COOPER, 2004, p. 220), é problemático no contexto das sociedades dilaceradas pela guerra. Esse modelo - imposto de fora para dentro através da "administração internacional, das condicionalidades dos doadores internacionais e da propaganda triunfante do livre mercado" (PUGH; COOPER, 2004, p. 225) submete as sociedades fragmentadas pelo conflito a uma dupla penalização: o policiamento econômico eficaz, concentrado na repressão às atividades ditas 'ilícitas', retira trabalho e renda de grande parte das famílias, enquanto os ajustes estruturais macroeconômicos ${ }^{9}$ enfraquecem o papel do Estado, reduzindo a sua capacidade de

\footnotetext{
9 Baseados na privatização, no investimento estrangeiro e na desregulamentação do
} mercado (PUGH; COOPER, 2004, p. 200). 
prover meios alternativos de subsistência às populações empobrecidas" (PUGH; COOPER, 2004, p. 201). Desse modo, concluem Pugh e Cooper, o modelo liberal de intervenção falha em três aspectos fundamentais: não compreende o papel das economias subterrâneas e de sobrevivência; não percebe a necessidade de uma abordagem regional abrangente; e reduz a capacidade institucional do Estado para atuar na proteção das populações vulneráveis, na provisão de serviços públicos essenciais e na condução do crescimento econômico (PUGH; COOPER, 2004, p. 220).

Do ponto de vista da transformação de conflitos, portanto, a economia política liberal que orienta o modelo de intervenção internacional acaba por reforçar as desigualdades socioeconômicas dentro de um contexto de fragilidade institucional. Em consequência, elevados níveis de pobreza e novas formas de economias subterrâneas e de sobrevivência persistem, acabando por produzir, a médio e longo prazo, "a institucionalização da violência estrutural" e as condições propícias para a eclosão de novos conflitos (PUGH; COOPER, 2004, p. 201).

\section{Economia política da pirataria na Somália: um estudo de caso}

A atual situação do conflito na Somália torna praticamente nula a possibilidade de ingresso de pesquisadores estrangeiros para a realização de estudo de campo naquele país. Desse modo, a exemplo do que ocorre no estudo de zonas de guerra em geral, ${ }^{10}$ a escassez de dados empíricos é uma realidade com que se defronta esta tentativa de compreensão da dimensão político-econômica da pirataria na Somália. Apesar dessa dificuldade, um conjunto de fontes complementares ${ }^{11} \mathrm{e}$

\footnotetext{
${ }^{10}$ Para ampliar a compreensão dos desafios metodológicos à pesquisa em zonas de guerra, ver Goodhand (2000); Vlassenroot (2005).

${ }^{11}$ As principais fontes de dados empíricos que sustentam este estudo de caso são: (1) Monitoring Group on Somália (grupo vinculado ao Conselho de Segurança da ONU), cujos relatórios são produzidos, geralmente, a partir de pontos de coleta de dados localizados no Quênia e com a contribuição de redes de informantes locais com acesso à Somália; (2) Organizações Marítimas Internacionais, cujos relatórios são produzidos a partir dos dados informados pelas companhias de navegação, companhias de seguro, tripulações e passageiros dos navios alvos de ataques de pirataria; e (3) entrevistas concedidas por piratas e reportagens jornalísticas publicadas em consagrados órgão da imprensa internacional.
} 
alguns estudos acadêmicos já realizados permitem traçar um quadro consistente da economia política da pirataria na Somália compatível com os propósitos deste estudo de caso. Feita essa nota de caráter metodológico, a pirataria na Somália é mapeada a seguir dentro da tipologia de economias de guerra proposta por Pugh e Cooper, destacando-se, quando for pertinente, as suas conexões regionais.

\subsection{Contextualização histórica}

A República da Somália nasceu em 1960, pondo fim à administração colonial até então partilhada entre o Reino Unido e a Itália. Após uma primeira década de regime democrático, um golpe de estado liderado pelo General Muhammad Siyad Barre, em 1969, deu início a uma ditadura militar orientada, em seu momento inicial, pela retórica do 'socialismo científico', oficialmente batizada pela expressão 'compartilhamento da riqueza com base no conhecimento.' ${ }^{12}$ Essa orientação ideológica - fortemente influenciada pela ajuda militar soviética e pelo apoio de uma jovem classe de intelectuais somalis decepcionada com a orientação pró ocidental do período anterior - vigorou durante sete anos e garantiu um relativo grau de estabilidade interna no país. Em 1977, porém, devido ao apoio militar soviético prestado à Etiópia, contra os interesses da Somália, na guerra pela disputa da região fronteiriça de Ogaden, ${ }^{13}$ as ligações entre o governo de Siyad Barre e o regime de Moscou deterioraram-se. Em 1978, com a vitória da Etiópia na disputa pela região de Ogaden, amplamente suportada pela ajuda soviética e cubana, o regime de Siyad Barre assumiu um franco posicionamento pró ocidental sem, contudo,

\footnotetext{
${ }^{12}$ Tradução do autor para a expressão 'wealth-sharing based on knowledge', conforme foi oficialmente denominada a ideologia socialista implementada na Somália pelo regime do general Siyad Barre (LEWIS, 2008, p. 39).

${ }^{13}$ Região de maioria étnica somali pertencente à Etiópia, onde um movimento intitulado 'Frente de Libertação da Somália Ocidental' (FLSO) defendia, desde 1974, a autodeterminação através da luta armada. As ligações familiares de Siyad Barre aos clãs de Ogaden e seu discurso anti-imperialista contra a Etiópia levaram a Somália, em 1977, a invadir a fronteira oriental do país vizinho, sob o pretexto de apoiar a FLSO. Esse ato deu início ao conflito com a Etiópia e levou, num primeiro momento, à ocupação da região pela Somália. Porém, diante da reação etíope, suportada militarmente pela União Soviética e por Cuba, a Somália saiu derrotada da guerra, tendo o território de Ogaden sido reocupado pela Etiópia no ano seguinte (HEALY, 2010, p. 375-6).
} 
obter dos Estados Unidos o mesmo tipo de ajuda militar recebida anteriormente no período de aproximação com a União Soviética. Desde então, tendo que enfrentar os efeitos da derrota na Guerra de Ogaden (a perda de popularidade, o grande influxo de refugiados de etnia somali vindos das regiões reocupadas pela Etiópia, e o renascimento da política de clãs), o regime de Siyad Barre perdeu a sua força e atravessou os anos 1980 sob a pressão de forte oposição armada. Essa oposição culminou em 1991 com a deposição de Siyad Barre e o desmantelamento do governo central na Somália. A partir daí, o país fragmentou-se e mergulhou num conflito entre clãs que se prolonga até a atualidade (LEWIS, 2008, p. 33-74; HEALY, 2010, p. 372-78).

O problema da pirataria na Somália é, em grande medida, resultado desse processo histórico. Durante a ditadura de Siyad Barre, o controle do rico mar territorial da Somália ${ }^{14}$ foi exercido com base numa pequena Marinha encarregada de fiscalizar as atividades exercidas pelos pescadores locais, operar a 'venda' de licenças de pesca à companhias estrangeiras e monitorar o acesso aos portos no país, que serviam como pontos de apoio aos navios em trânsito na estratégica rota mercante $^{15}$ que passa ao largo da costa somali (WEIR, 2010, p. 209-10). Com o fim do regime de Siyad Barre e início da guerra civil, a presença na região das forças navais associadas às duas operações de peacekeeping das Nações Unidas ${ }^{16}$ continuou a exercer, durante a primeira metade dos anos 1990, a função de patrulhamento naval que a Marinha somali, então desmantelada, não mais podia desempenhar (WEIR, 2010, p. 210).

Em 1995, com a retirada da operação das Nações Unidas da Somália (UNOSOM II) sem ter conseguido um acordo de paz entre as facções em combate, e com a falta de uma autoridade central capaz de exercer o monopólio da força e ordenar a exploração dos recursos marinhos nas águas territoriais da Somália, sérios danos

${ }^{14} \mathrm{O}$ mar territorial da Somália é abundante em recursos pesqueiros e, além de tradicionalmente servir como base económica das comunidades costeiras, foi oficialmente explorado como fonte de receitas na ditadura de Siyad Barre, através da 'venda' de licenças de pesca a navios estrangeiros (WEIR, 2010, p. 209).

${ }^{15}$ Ligando o Oceano Índico ao Mar Vermelho e Canal de Suez.

${ }^{16}$ United Nations Operation in Somalia I (UNOSOM I), desenvolvida em 1992-1993, e United Nations Operation in Somalia II (UNOSOM II), desenvolvida entre 1993 e 1995. 
econômicos e ecológicos foram provocados na região. Aproveitando-se da total falta de fiscalização e controle do Estado, o mar territorial da Somália tornou-se um paraíso para a exploração da pesca industrial por navios estrangeiros; além disso, a região passou a ser usada como depósito de resíduos tóxicos e poluentes (UNITED NATIONS, 2008a, p. 28). Essa exploração intensiva da pesca e a degradação ambiental levaram à redução de recursos pesqueiros na região, produzindo dois efeitos nas populações locais: criaram um forte ressentimento contra os navios pesqueiros estrangeiros e deixaram sem trabalho antigos pescadores que se utilizavam da pesca para o sustento de suas comunidades (NINCIC, 2009, p. 9). Em consequência, alguns desses pescadores passaram a preencher o vácuo deixado pela ausência do Estado na tarefa de patrulhamento do mar territorial da Somália, adotando atitudes hostis contra os navios pesqueiros encontrados na região. Essa situação não tardou a alimentar a cobiça de líderes de milícias em terra, que passaram a instrumentalizar os antigos pescadores em prol de um lucrativo negócio de 'venda' de licenças de pesca na região. Aos navios que não concordavam com o pagamento, tais milícias marítimas começaram a responder com ameaças de sequestro, criando o tipo de procedimento que, mais tarde, passou a ser aplicado em larga escala contra os navios mercantes e de lazer em trânsito na região (WEIR, 2010, p. 210-11). Essas origens do problema, situadas entre 1995 e 2000 (WEIR, 2010, p. 210), continuam a inspirar os piratas da atualidade e servem para legitimar suas atividades aos olhos das comunidades locais. Neste sentido, o discurso que prevalece entre os piratas é que as suas ações apenas buscam ressarcir as comunidades costeiras pelos prejuízos causados por anos de ação predatória dos navios estrangeiros no mar territorial da Somália (WALDO, 2009; BENGALI, 2009; GETTLEMAN, 2008).

Ainda que as origens da pirataria somali remontem à década de 1990, o problema adquire dimensões sem precedentes a partir de 2007 e 2008. De um problema inicialmente doméstico, localizado nas proximidades do litoral e geralmente dirigido contra navios de pesca estrangeiros, a ação dos piratas deslocou-se para além dos limites do mar territorial e passou a visar grandes navios mercantes em trânsito na região (UNITED NATIONS, 2008a, p. 27). Comparado a outras regiões de pirataria endémica - como o Mar do Sul da China, o Estreito de Malaca e a costa da Nigéria, por exemplo - o modus operandi da pirataria na Somália é peculiar: 
em vez de roubos de cargas ou de bens pessoais dos tripulantes e passageiros, como tipicamente ocorre nos ataques de pirataria nas demais regiões, a pirataria na Somália tem por objetivo o sequestro em troca de resgate. Por essa razão, os níveis de violência física no caso da pirataria somali são relativamente baixos se comparados ao tipo de ataque que predomina nas outras regiões. Afinal, a preservação da vida dos tripulantes e passageiros, bem como a conservação da integridade da carga, são as garantias de que o resgate será pago pelos armadores e governos estrangeiros (INTERNATIONAL EXPERT GROUP ON PIRACY OFF THE SOMALI COAST, IEG, 2008, p.14).

\subsection{Economia subterrânea}

As operações de pirataria na Somália têm suas bases localizadas em duas áreas: litoral da região central da Somália e costa de Puntland, situada na região nordeste do país. Na primeira região, opera uma rede de pirataria liderada por Mohamed Hassan Abdi 'Afweyne', tendo como bases principais as cidades de Xarardheere e Hobyo. Essa área litorânea, juntamente com o restante da região central e o sul do país, constitui a zona de maior turbulência na Somália e caracteriza-se por um contexto onde se misturam a ausência do Estado, ${ }^{17}$ a insurgência fundamentalista islâmica, as lutas de clãs e uma proliferação de milícias e 'senhores da guerra'. Essa situação cria as condições propícias para o recrutamento de piratas (em grande parte ex-pescadores incentivados pela alternativa de dinheiro rápido) e para a organização e condução das operações de pirataria dentro de um clima de violência, corrupção e impunidade. Dentro desse ambiente, deve-se destacar que a pirataria na região conecta-se a diversos negociantes locais e 'senhores da guerra' para a obtenção de barcos, combustível, armas, munição e equipamentos de comunicação (UNITED NATIONS, 2008a, p. 30).

\footnotetext{
${ }^{17}$ Analistas têm destacado o fato do Governo Federal de Transição na Somália (GFT) não contar com qualquer legitimidade local e não conseguir controlar mais do que alguns quarteirões em Mogadíscio com o apoio das tropas da missão da União Africana (SCHOFIELD, 2008, p. 111-2). Além disso, há cada vez mais evidências de corrupção e perda de autoridade do GFT (UNITED NATIONS, 2008a, p. 43-4).
} 
$\mathrm{Na}$ região nordeste, outra rede de pirataria está organizada em torno da cidade de Eyl e tem como um de seus líderes principais Farah Hirsi Kulan 'Boyah' (UNITED NATIONS, 2008a, p. 30). Enquanto a rede baseada no litoral central da Somália desenvolve-se num contexto de turbulência e aproveita-se da ausência do Estado para proliferar, a rede baseada no litoral nordeste, ao contrário, desenvolve-se numa região de relativa estabilidade política, com um governo funcional estabelecido desde 1998, quando a Pultland declarou sua autonomia política. Porém, ainda que o atual governo de Puntland adote uma retórica de rejeição à pirataria, há evidências de que figuras proeminentes, como o próprio Presidente Faroole e diversos Ministros do seu gabinete, têm recebido recursos provenientes dos sequestros a navios para, em troca, tolerarem as práticas de pirataria e garantirem a impunidade aos piratas e seus líderes (UNITED NATIONS, 2010, p. 39-42).

Quanto às conexões regionais, merece relevo a ligação entre a pirataria sediada no litoral central e o tráfico de armas procedente do Iêmen em direção aos portos de Xarardheere e Hobyo, portos que são considerados duas das mais importantes portas de ingresso de carregamentos de armas destinadas às milícias e às facções em luta na Somália e na Etiópia (UNITED NATIONS, 2008a, p. 30-32). Merecem destaque, ainda, as ligações identificadas entre um grupo de piratas sediado na região de Bari (Puntland) e o tráfico de armas e de seres humanos através do Golfo de Aden. Segundo um relatório do 'UN Monitoring Group on Somalia', "os mesmos barcos empregados nos ataques piratas são usados para transportar refugiados e emigrantes econômicos da Somália para o Iêmem, trazendo armas e munições na viagem de volta” (UNITED NATIONS, 2008a, p. 30-32). O mais recente relatório do 'UN Monitoring Group on Somalia' destaca, ainda, que diversos piratas baseados em Puntland obtiveram, em 2009, vistos de entrada em países europeus e que, após terem viajado à Suécia, Holanda e Reino Unido, regressaram à Somália para reassumir suas funções na pirataria (UNITED NATIONS, 2010, p. 36). A respeito do deslocamento de piratas ao estrangeiro, diversas fontes mediáticas reportaram, em 2009, a viagem à Tripoli de um grupo de piratas, dentre os quais Afweyne, líder da rede de pirataria baseada em Xarardheere e Hobyo, a convite do próprio Presidente da Líbia Mu’ammar Qadafi. Antes da Assembléia Geral das Nações Unidas em Setembro de 2009, o líder líbio confirmou esse encontro realizado meses antes, falou em defesa dos piratas e conclamou todos os Estados a 
respeitarem a zona económica exclusiva da Somália” (UNITED NATIONS, 2010, p. 39). Embora não haja ainda evidências que esclareçam os objetivos concretos dessas viagens, isso pode indicar que piratas e seus líderes estão viajando ao exterior para "conduzir seus negócios, encontrar investidores ou branquear seus ganhos ilícitos, aplicando-os em capitais na Europa (EICHSTAEDT, 2010, p. 177). Destaca-se, finalmente, a proliferação de um serviço regional de courier, cada vez mais utilizado para o pagamento de resgates, não só dos sequestros a estrangeiros realizados em terra, mas também de sequestros a navios realizados pelos piratas. Grande parte desse serviço parte do Quênia e conecta-se, na fronteira com a Somália, com mensageiros que se encarregam de completar o pagamento diretamente aos líderes piratas ou usando intermediários, tais como líderes dos clãs, líderes religiosos, homens de negócio ou autoridades do governo de Puntland (UNITED NATIONS, 2008a, p. 50-1).

\subsection{Economia de sobrevivência}

O pirata somali é recrutado, geralmente, entre os jovens pobres, desempregados e sem escolaridade nas comunidades costeiras, nos vilarejos vizinhos e, em menor escala, no interior do país (IEG, 2008, p. 17). Essa mão de obra enquadra-se, basicamente, em três perfis de piratas: o detentor de habilidades de navegação e conhecedor profundo do mar, normalmente recrutado entre os pescadores das comunidades costeiras; o jovem desocupado e sem habilidades específicas em busca de alguma alternativa de vida; e o detentor de habilidades mais agressivas, geralmente oriundo das milícias dos clãs (GILPIN, 2009, p. 6). É interessante notar, ainda, casos de piratas, em geral provenientes de clãs nômades e baseados no interior do país, que nem sequer sabem nadar. Ainda que essa condição implique numa posição hierárquica inferior e dê direito a apenas um salário básico (IEG, 2008, p. 18), a pirataria continua a ser uma opção vantajosa diante dos problemas de sobrevivência que tais jovens têm de enfrentar. Em todas essas siruações, a pirataria surge como uma alternativa rápida para obtenção de recursos por pessoas submetidas à pobreza extrema, à falta de opções de emprego, à degradação ambiental, à redução de pastagens para a criação de animais devido às constantes secas e à escassez de recursos pesqueiros devido à pesca 'ilegal' e 'predatória' por 
companhias estrangeiras (IEG, p. 15). Desse modo, ainda que a pirataria ofereça riscos, os benefícios são compensadores diante das dificuldades extremas com que essas pessoas e suas famílias se deparam no dia-a-dia.

Além dessa mão de obra diretamente empregada nas operações de pirataria, a comunidade, de modo geral, beneficia-se dos recursos gerados. Aí incluem-se não só as famílias dos piratas, mas também toda a cadeia de apoio que provê alimentação, água, e outros itens básicas aos piratas e também às tripulações e passageiros sequestrados (IEG, p. 17). Um artigo de Howden e Guled (2008), publicado no jornal inglês The Independent, é esclarecedor sobre os efeitos da pirataria junto às comunidades locais. Em Eyl, dizem os autores, "a população vive na cadência dos ataques contra navios estrangeiros; apoia os piratas e admira a sua coragem". Praticamente todos na cidade têm parentes na pirataria; além disso, em torno dessa atividade nasce uma infraestrutura que beneficia e sustenta a população local, como por exemplo os "restaurantes que fornecem a alimentação aos tripulantes e passageiros sequestrados".

\subsection{Economia de combate}

A Al-Shabaab é uma das principais organizações armadas de oposição ao Governo Federal de Transição na Somália, tendo adquirido grande proeminência em 2005/2006, quando emergiu como o braço militar da União das Cortes Islâmicas (UCI). Após a derrota da UCI pelas forças etíopes em 2007 e restauração do Governo Federal de Transição em Mogadíscio, a Al-Shabaab adotou uma trajetória cada vez mais independente, procurando assumir uma orientação fundamentalista radical próxima à Al-Qaida. ${ }^{18}$ Essa orientação tem levado alguns países ocidentais a classificarem a Al-Shabaab como organização terrorista (UNITED NATIONS, 2010, p. 15).

\footnotetext{
${ }^{18}$ Diversos líderes do grupo têm sido treinados ou têm lutado ao lado da Al-Qaida, principalmente no Afeganistão, trazendo para a Somália as táticas empregadas por aquela organização terrorista (UNITED NATIONS, 2010, p. 15).
} 
Alguns especialistas sobre a Somália têm destacado os crescentes indícios de ligação entre a pirataria e a Al-Shabaab, apontando para uma mudança da postura anti-pirataria daquela organização, tal como havia sido demonstrada à época de sua aliança com a União das Cortes Islâmicas. Segundo esses indícios, a aproximação da Al-Shabaab aos piratas é motivada pela necessidade de treinamento e obtenção das habilidades marítimas para que a própria organização assuma a tarefa de contrabando de armas para o movimento. As mesmas fontes, porém, advertem que essa "sinergia operacional" restringe-se a alguns piratas da rede baseada em Xarardheere, cuja origem familiar remonta aos mesmos clãs dos integrantes da Al-Shabaab. Desse modo, essa conexão é um fenômeno localizado e não pode ser estendida à rede de pirataria baseada em Pultland (IEG, 2008, p. 21).

Recentes fontes jornalísticas têm reforçado essa conexão entre a pirataria e a luta armada na Somália, destacando a aproximação cada vez maior entre a Al-Shabaab e os piratas, que já se traduz em palavras de ordem do tipo "guerra santa no mar" e incentivos aos jovens militantes para que ingressem na pirataria para atacar "navios americanos" (CHILDRESS, 2009). Nesse mesmo sentido, Alan Cole, coordenador do programa contra a pirataria das Nações Unidas sediado em Nairobi, destaca o fato de, recentemente, alguns piratas terem sido capturados no mar sem alimentos, água e combustível e, aparentemente, sem demonstrarem os conhecimentos básicos sobre o mar, o que leva a crer que "o nível de proficiência está caindo, na medida que há menos pescadores e mais combatentes envolvidos nas operações de pirataria" (CHILDRESS, 2009). Outra fonte destaca que a noção da pirataria na Somália como mero oportunismo já não se aplica à realidade. Segundo essa fonte, a rede de pirataria estabelecida em Hobyo aplica cada vez mais recursos no reinvestimento em barcos, armas mais pesadas e na constituição de poderosas milícias marítimas e terrestres. Com verdadeiras "forças armadas", os piratas não mais podem assumir uma posição neutra e "estão agora tomando partido" (GETTLEMAN, 2010).

Ainda que essas conexões sejam cada vez mais ressaltadas por especialistas, o mais recente relatório do UN Monitoring Group on Somália afirma não ter encontrado em suas investigações "quaisquer evidências que suportem as alegações de uma cooperação estruturada entre os grupos de piratas e os grupos de oposi- 
ção armada, inclusive a Al-Shabaab". Segundo esse relatório, ainda que algumas ligações desse tipo possam ser confirmadas, "elas representam um fenômeno altamente localizado, resultante de pequenos arranjos entre indivíduos", não havendo, portanto, evidências que apontem para "um padrão mais abrangente" (UNITED NATIONS, 2010, p. 37).

Com base neste estudo de caso, pode-se constatar que, antes da pirataria representar uma simples 'patologia local', ela segue uma racionalidade plenamente integrada ao contexto histórico, ao ambiente sócio-político-econômico atual da Somália e ao 'complexo regional de conflitos' da região do Chifre da África. Desse modo, o comportamento econômico das elites envolvidas na pirataria e de todos aqueles que dela dependem não pode ser entendido meramente como 'o desvio da norma', mas sim como o estabelecimento de um sistema econômico alternativo, ajustado à realidade local e regional. Tal como alertam Pugh e Cooper (2004, p. 7), as atividades compreendidas pelas economias de guerra "podem não parecer racionais do ponto de vista da economia política convencional" baseada nos "critérios de mercado das economias capitalistas ocidentais". Porém, do ponto de vista da economia política dos conflitos, a participação nas economias de guerra é resultado, também, de cálculos racionais e guia-se, permanentemente, pela avaliação dos benefícios funcionais obtidos em relação aos riscos envolvidos. No caso da pirataria na Somália, os benefícios gerados não só às elites, mas também a todos aqueles que dela dependem para enfrentar as dificuldades de sobrevivência, compensam amplamente os riscos envolvidos.

\section{Por uma agenda transformativa da pirataria na Somália}

A principal resposta internacional dada à onda de pirataria nas costas da Somália é a intervenção naval patrocinada pelas Nações Unidas que se encontra em curso há praticamente dois anos. Essa intervenção foi originada em 2008, quando o Conselho de Segurança das Nações Unidas emitiu um conjunto de resoluções (UNITED NATIONS, 2008c), chamando a atenção internacional para o aumento na incidência de atos de pirataria nas costas da Somália e autorizando os Estados interessados em manter a segurança marítima na região a implementarem as seguintes medidas: 
(a) Entrar no mar territorial da Somália com o propósito de reprimir atos de pirataria e roubo armado no mar [...]; e

(b) Usar, dentro do mar territorial da Somália, [...] todos os meios necessários para reprimir atos de pirataria e roubo armado no mar. $^{19}$

Em resposta a essas resoluções, diversas operações navais de combate à pirataria - conduzidas pela iniciativa independente de alguns Estados (Japão, China, Federação Russa, Índia, Malásia, República da Coréia, Arábia Saudita, República Islâmica do Iram e Iêmen) e pelo esforço combinado de três coalizões marítimas internacionais (United States-led Combined Maritime Forces, NATO standing maritime forces e European Union Naval Force Operation Atlanta) - foram iniciadas no final de 2008 e intensificadas ao longo de 2009 e 2010 (UNITED NATIONS, 2010).

Examinando as resoluções do Conselho de Segurança e as operações navais por elas desencadeadas, nota-se que a ação internacional contra a pirataria na Somália concentra-se na dimensão militar e tem por objetivo reprimir a violência direta que se manifesta no mar. Desse modo, a pirataria é tratada como mera disfunção, como uma anomalia que, se corrigida, produz um melhor funcionamento da ordem internacional estabelecida na região. O problema dessa abordagem, vista de um ponto de vista crítico (COX, 1996), é que ela oferece um quadro fixo de ação, ou seja, um quadro estático da pirataria, onde o problema é reduzido aos seus efeitos. Dentro de tais limites, não há margem para a acção transformadora, pois as condições históricas que produziram o problema e as dinâmicas que tornam a pirataria uma atividade econômica atrativa na Somália deixam de ser consideradas.

Ao observar essas condições históricas e as dinâmicas político-econômicas da pirataria, tal como foi feito no estudo de caso da seção anterior, constata-se que a pirataria na Somália desempenha um leque de funções ligadas à economia sub-

${ }^{19}$ Tradução nossa: “(a) Enter into the territorial waters of Somalia for the purpose of repressing acts of piracy and armed robbery at sea [...]; and (b) Use, within the territorial waters of Somalia [...] all necessary means to repress acts of piracy and armed robbery at sea." (UNITED NATIONS, S/RES 1846, 2008c) 
terrânea, à economia de sobrevivência e, em menor escala, à economia de combate. Essas economias desenvolvem-se através de variadas conexões locais e regionais, envolvendo relações com 'senhores da guerra', corrupção de autoridades governamentais, tráfico de armas, contrabando, tráfico de seres humanos, branqueamento de capitais, movimento de armas para as facções em conflito, e etc. Para, além disso, o exame da economia política da pirataria torna clara a sua função social, demonstrando que as suas atividades criam oportunidades de emprego e estruturas alternativas de serviços que possibilitam o enfrentamento das condições de pobreza e marginalização de parcela considerável das populações que vivem em torno das bases da pirataria. Diante desse quadro, é-se forçado a admitir que a ação internacional, ao concentrar-se no patrulhamento naval nas costas da Somália, não é capaz de tratar a pirataria dentro do contexto complexo que envolve todos os aspectos político-econômicos aqui identificados.

O ponto fundamental a destacar, portanto, é a insustentabilidade dessa intervenção naval, onde a pirataria é tratada como mera questão de pacificação de focos de desordem no mar. Esse tipo de resposta, embora tenha produzido, em 2009, uma redução de $22 \%$ na quantidade de sequestros bem sucedidos em relação ao ano anterior, não conseguiu evitar que a quantidade de tentativas de ataques dos piratas aumentasse 95\% no mesmo período. Além disso, observou-se no primeiro semestre de 2010 que o principal efeito das operações navais foi deslocar a ação dos piratas da região do Golfo de Aden (onde predominavam os ataques em 2008/09) para regiões mais distantes no Oceano Índico (UNITED NATIONS, 2010, p. 36). Portanto, ainda que as operações navais consigam frustrar parte dos sequestros, os incentivos político-econômicos que alimentam a pirataria continuam presentes na Somália, o que reforça a constatação, já anunciada na seção anterior, de que os benefícios da pirataria ainda compensam os riscos oferecidos pelo patrulhamento naval na região.

Esse quadro geral sugere que uma resposta sustentável ao problema da pirataria na Somália não pode ser baseada exclusivamente nas medidas de coerção e na criminalização dos piratas e daqueles que se beneficiam da pirataria. A abor- 
dagem 'problem solving' ${ }^{20}$ que caracteriza a atual intervenção naval na costa somali simplifica o problema e não dá conta das dinâmicas de sobrevivência, lucro e condução da guerra que se sobrepõem e se reforçam mutuamente no contexto que envolve a pirataria na Somália. Portanto, somente uma abordagem abrangente, voltada para a transformação dessas dinâmicas, pode construir respostas sustentáveis. Isso implica, em termos de formulação de políticas, numa reorientação da agenda da pirataria na Somália para um sentido transformativo que seja capaz de criar desincentivos à violência e, ao mesmo tempo, incentivos que conduzam os atores envolvidos na pirataria a adotarem alternativas econômicas mais pacíficas.

\section{Conclusão}

As análises realizadas neste artigo levam a três constatações principais. Primeiramente, antes de representar uma anomalia funcional na ordem estabelecida numa das principais rotas do comércio marítimo internacional, a pirataria na Somália representa, também, a construção de um sistema econômico alternativo, racionalmente integrado às condições históricas, ao ambiente sócio-político-econômico da Somália e ao complexo regional de conflitos em vigor na região do Chifre da África. Desse modo, o comportamento econômico das elites envolvidas na pirataria e daqueles que dela dependem não pode ser entendido exclusivamente do ponto de vista do 'desvio da norma', mas deve ser visto também como uma adaptação a um sistema político-econômico alternativo. Nesse sistema, os meca-

${ }^{20}$ Cox distingue dois tipos de teoria: 'problem solving' e 'critical theory'. Segundo o autor, as abordagens 'problem solving' (solução de problemas) têm por propósito guiar a solução de problemas específicos, bem delimitados dentro de uma moldura analítica fixa e imutável (1996, p. 88). Estas abordagens preservam a ordem internacional dominante, pois consideram as relações sociais e de poder, bem como as instituições onde estas relações estão organizadas, como um quadro fixo de acção (1996, p. 88). A 'critical theory' (teoria crítica), por outro lado, é questionadora e reflexiva. Ela não toma a ordem dominante como fixa, mas questiona a origem de suas instituições e a forma como suas relações sociais e de poder estão organizadas. Isto não quer dizer que a teoria crítica se limita a apresentar críticas sem se comprometer com a solução dos problemas. Ao contrário, ela também se envolve com problemas específicos, porém, procura entendê-los a partir dos processos históricos que os produziram. É dentro deste contexto que surge o conhecimento necessário para guiar a acção política transformadora (COX, 1996, p. 150). 
nismos de sobrevivência, acumulação de riqueza e condução da guerra misturam-se e reforçam-se uns aos outros, tornando os benefícios funcionais da pirataria compensadores em relação aos riscos envolvidos.

Em segundo lugar, a intervenção naval contra a pirataria em curso na costa somali desde o final de 2008, ao concentrar-se na violência direta que se manifesta no mar, deixa de contemplar as dinâmicas que estão na base da economia política da pirataria na Somália. Por essa razão, ainda que tal intervenção consiga impedir a concretização de alguns sequestros, ela não consegue atuar nas condições que tornam a pirataria uma atividade atrativa na Somália. Desse modo, os resultados alcançados com dois anos de patrulhamento naval são relativos e resumem-se à redução parcial na quantidade dos sequestros bem sucedidos e à prisão de piratas. Essa medida, porém, não conseguiu evitar o aumento significativo na quantidade de tentativas de ataques ocorridos em 2009 e o deslocamento das ações de pirataria para regiões mais afastadas no Oceano Índico a partir deste ano.

Em terceiro lugar, somente uma abordagem abrangente, voltada para a transformação das dinâmicas que alimentam a economia política da pirataria na Somália, pode construir respostas sustentáveis para o problema. Isso representa, em termos de formulação de políticas, a uma reorientação da agenda da pirataria na Somália para um sentido transformativo que busque criar mecanismos que desincentivem a violência e incentivem a adoção de alternativas econômicas mais pacíficas. Esse caminho, longe de simplificar as coisas, apresenta na verdade um grande desafio: a necessidade fundamental de substituição das receitas intervencionistas impostas de fora para dentro por abordagens alternativas que privilegiem as esferas local e regional e destinem aos somali um papel de protagonismo na formulação e implementação das políticas voltadas para o tratamento do problema da pirataria. 


\section{Political economy of piracy in Somalia: basis for a transformative approach}

\section{Abstract}

This article examines the current wave of piracy off the coast of Somalia in light of political economy framework proposed by Michael Pugh and Neil Cooper. According to these authors, three types of economies flourish in protracted conflicts - combat economy, shadow economy, and coping economy - whose aims are, respectively, to finance combat activities, generate personal profits and provide minimum resources to the subsistence of poor and marginalized people. Based on empirical evidences showing that piracy in Somalia performs these three functions, one argues that the current international intervention against piracy is not sustainable because it does not seek to transform the factors and dynamics that make piracy an economically attractive alternative for local populations. For this reason, one proposes a shift on the Somali piracy agenda by adopting a critical perspective where piracy is no longer treated exclusively as a mere disruption of order at sea. Instead, one suggests a transformative approach where piracy is understood in its political economy dimension taking into account not only the local aspects, but also their regional links.

Keywords: War economies. Piracy in Somalia. Conflict transformation.

\section{Referências}

ANDERSEN, Lars Erslev. Piracy in the Gulf of Aden: reflections on the concepts of piracy and order. In: HVDT, Nanna; MOURITZEN, Hans (Org.) Danish Foreign Policy Yearbook 2009. Copenhagen: DIIS, 2009. p. 79-106

AZAR, Edward. The management of protracted social conflict: theory and cases. [s.l.]: Aldershot: Dartmouth, [s.d]

BALLENTINE, Karen. Beyond Greed and Grievance: reconsidering the economic dynamics of armed conflict. In: BALLENTINE, Karen; SHERMAN, Jake. The political Economy of Armed Conflict: Beyond Greed and grievance. London: Lynne Rienner, 2003. p. 259-283. 
BALLENTINE, Karen; SHERMAN, Jake. The political Economy of Armed Conflict: beyond greed and grievance. London: Lynne Rienner, 2003.

BENGALI, Shashank. An interview with a jailed Somali pirate leader, Christian Science Monitor, 2009. Disponível em: <http://www.csmonitor.com/World/ Africa/2009/0503/p06s12-woaf.html>. Acesso em: 20 nov. 2009.

BERDAL, Mats; MALONE, David M. (Org.). Greed and Grievance: economic agendas in civil wars. Boulder: Lynne Rienner, 2000.

BUZAN, Barry; W????VER, Ole; WILDE, Jaap. Security: a new framework for analysis. London: Lynne Rienner Publishers, 1998.

CATER, Charles. The Political Economy of Conflict and UN Intervention: rethinking the critical cases of Africa. In: BALLENTINE, Karen; SHERMAN, Jake. The political economy of armed conflict: beyond greed and grievance. London: Lynne Rienner, 2003. p. 19-45.

COLLIER, Paul. Doing Well out of War: an economic perspective. In: BERDAL, Mats; MALONE, David M. (Org.). Greed and Grievance: economic agendas in civil wars. Boulder: Lynne Rienner, 2000. p. 91-111.

COLliER, Paul; HOEFFLER, Anke. On Economic Causes of Civil War, Oxford Economic Papers, v. 50, p. 563-573, 1998.

CHILDRESS, Sarah. Somali Militants Try Piracy to Fund Attacks. The Wall Street Journal, 2009. Disponível em: <http://online.wsj.com/article/SB100014240527487 03720004575477491009472882.html>. Acesso em: 10 set. 2010.

COX, Robert W. Approaches to world order. Cambridge: Cambridge University Press, 1996.

EICHSTAEDT, Peter. Pirate State: inside Somalia's terrorism at sea. Chicago: Lawrence Hill Books, 2010.

GETTLEMAN, Jeffrey. Somali Pirates Tell Their Side: They want Only Money, New York Times, 2008. Disponível em: <http://www.nytimes.com/2008/10/01/world/ africa/01pirates.html>. Acesso em: 20 nov. 2009.

GETTLEMAN, Jeffrey. In Somali Civil War, Both Sides Embrace Pirates, New York Times, 2010. Disponível em: <http://www.nytimes.com/2010/09/02/world/ africa/02pirates.html>. Acesso em: 20 set. 2010. 
GILPIN, Raymond. Counting the Costs of Somali Piracy. United States Institute of Peace. Disponível em: <http://www.usip.org/resources/counting-the-costs-somalipiracy>. Acesso em: 20 dez. 2009.

GOODHAND, Jonathan. Research in Conflict Zones: Ethics and Accountability. Forced Migration Review, v. 8, p. 12-15, 2000

GOODHAND, Jonathan. Afghanistan in Central Asia. In: PUGH, Michael; COOPER, Neil. War Economies in a Regional Context: Challenges of Transformation. London: Lynne Rienner, 2004. p. 45-89.

HEALY, Sally. Reflections on the Somali State: What went wrong and why it might not matter. In: HOEHNE, Markus; LULING Virginia (Org.) Milk and Peace, Drought and War: Somali Culture, Society and Politics. London: Hust and Company, 2010. p. 84-376.

HOWDEN, Daniel; GULED, Abinasir Mohamed. Off the coast of Somalia: we're not pirates: these are our waters, not theirs. The Independent, 2008. Disponível em: <http://www.independent.co.uk/news/world/africa/off-the-coast-of-somaliawere-not-pirates-these-are-our-waters-not-theirs-1017962.html>. Acesso em: 14 nov. 2008.

INTERNATIONAL EXPERT GROUP ON PIRACY OFF THE SOMALI COAST (IEG). Piracy off the Somali Coast: Final Report 2008. Disponível em: <http:// www.imcsnet.org/imcs/docs/somalia_piracy_intl_experts_report_consolidated. pdf $>$. Acesso em: 20 nov 2009.

KALDOR, Mary. New and Old Wars: organized violence in a global era. Cambridge: Polity Press, 1999.

KEEN, David. The economic functions of violence in civil wars. Oxford: Oxford University Press, 1998.

KEEN, David. Incentives and desincentives for violence. In: BERDAL, Mats; MALONE, David M. (Org.). Greed and grievance: economic Agendas: in Civil Wars. Boulder: Lynne Rienner, 2000. p. 19-41.

LEWIS, Ioan. Understanding Somalia and Somaliland. London: Hurst \& Company, 2008.

NINCIC, Donna. Maritime piracy in Africa: The humanitarian dimension. African Security Review, v. 18, n. 3, p. 2-16, 2009. 
PUGH, Michael; COOPER, Neil. War economies in a regional context: challenges of transformation. London: Lynne Rienner, 2004.

RENO, William. Warlord Politics and African States. Boulder: Lynne Rienner, 1999.

RENO, William. "Shadow States and the political economy of civil wars". In: BERDAL, Mats; MALONE, David M. (Ed.). Greed and Grievance: Economic Agendas in Civil Wars. Boulder: Lynne Rienner, 2000. p. 43-68

SCHOFIELD, Clive. Plundered Waters: Somalia's Maritime Resource Insecurity. In: DOYLE, Timothy; RISELY, Melissa (Ed.) Crucible for Survival: Environmental Security and Justice in the Indian Ocean Region. New Jersey: Rutgers University Press, 2008.

THORUP, Mikkel. Enemy of Humanity: The Anti-Piracy Discourse in Present day Anti-Terrorism. Terrorism and Political Violence, v. 21, n.3, p. 11-401, 2009.

UNCLOS - United Nations Convention on the Law of the Sea, 1982. Disponível em: <http://www.un.org/Depts/los/convention_agreements/texts/unclos/closindx. htm> . Acesso em: 20 abr. 2010.

UNITED NATIONS. S/2008/769-Report of the Monitoring Group on Somalia pursuant to Security Council resolution 1811, 2008a. Disponível em: <http://www. unhcr.org/refworld/country,,,,SOM,,494900240,0.html>.Acesso em: 27 dez. 2008.

UNITED NATIONS. S/2009/590-Report of the Secretary-General pursuant to Security Council resolution 1846, 2008b. Disponível em: <http://www.un.org/ Docs/sc/sgrep09.htm>. Acesso em: 21 jan. 2010.

UNITED NATIONS. UN Security Council Resolutions 1816, 1838, 1844, 1846 e 1851, 2008c. Disponível em: <http://www.un.org/Docs/sc/unsc_resolutions08. htm> Acesso em: 21 jan. 2010.

UNITED NATIONS. S/2010/91-Report of the Monitoring Group on Somalia pursuant to Security Council resolution 1853/2008, 2010. Disponível em: <http:// somalitalkradio.com/2010/mar/un_report_somalia.pdf>. Acesso em: 15 jul. 2010.

VLASSENROOT, Koen. War and Social Research: The limits of empirical methodologies in war-torn environments. Civilisations, n. 54, p. 98-191, 2005. 
WALDO, Mohamed Abshir. The Two Piracies in Somalia: Why the World Ignores the Other?, 2009. Disponível em: <http://wardheernews.com/Articles_09/Jan/ Waldo/08_The_two_piracies_in_Somalia.html $>$. Acesso em: 2 fev. 2010.

WALLENSTEEN, Peter; SOLLEMBERG, Margareta. Armed conflict and regional conflict complexes, 1989-97. Journal of Peace Research, v. 35, n. 5, p. 621-634, 1998.

WEIR, Gary E. Fish, Family, and Profit. In: ELLEMAN, Bruce A.; FORBES, Andrew; ROSENBERG, David (Ed.) Piracy and Maritime Crime: Historical and Modern Case Studies. Newport: Naval war College Press, 2010. p. 207-221. 


\section{Para publicar na revista Universitas}

Relações Internacionais, entre no endereço eletrônico www.publicacoesacademicas.uniceub.br. Observe as normas de publicação, facilitando e agilizando o trabalho de edição. 